\title{
Variability in surface inversion characteristics over India in winter during the recent decades
}

\author{
U S IYER* and S G NAGAR \\ Indian Institute of Tropical Meteorology, Dr. Homi Bhabha Road, Pashan, Pune 411 008, India. \\ *e-mail: usha@tropmet.res.in
}

\begin{abstract}
The variation in surface inversions during the recent decades over 20 stations in the Indian region is documented. Radiosonde data at 00 UTC for the period 1971-2000 has been used to compute the inversion frequency. The depth and strength of the inversions as well as the wind speed through the inversion layer have also been computed. The frequency of inversions at stations north of $20^{\circ} \mathrm{N}$ is $\sim 20-60 \%$ higher than stations located south of $20^{\circ} \mathrm{N}$. Moreover, all the stations show frequencies increasing from the 1st to the 3rd decade. Most of the stations show decreasing depth and increasing strength significant at 99\% level. With the exception of Nagpur and Hyderabad which show high frequency of very deep inversions increasing from the 1st to the 3rd decade, the decadal variations of inversion depth at most of the other stations show that shallow and moderate inversions occur more frequently than deep or very deep inversions. Decadal variations in inversion strength show weak inversion frequencies decreasing from the 1st to the 3rd decade while moderate/strong inversions occur more frequently at most stations. Frequencies of very strong inversions are low or absent. Wind speeds are either weak or moderate with frequencies increasing from the 1st to the 3rd decade. Low frequency of strong winds and negligible frequency of very strong winds are observed.
\end{abstract}

\section{Introduction}

Long wave radiation emitted by the earth's surface at night cools the land much faster than the air above it thus trapping cold air at the surface and making the boundary layer stable. Additionally, when the nights are clear and winds are calm or light, occurrence of surface inversions in winter is a common feature. These inversion layers are destroyed in the day time due to insolation. By inhibiting vertical mixing, inversions play a significant role in the trapping and dispersal of pollutants. In the presence of ground inversions along with the surface concentration of pollutants, fog formation is a possibility if some moisture becomes available. Pollutants trapped at the surface pose a serious threat to the health of the public while reduced visibility due to fog is hazardous for aviation and surface transport. Therefore, knowledge of inversions may help in understanding the dispersal of pollutants and fog, both of which will immensely benefit the public at large, especially in the cities, which has expanded due to rapid growth in urban population and industrialization.

Several researchers have studied ground inversions/low level inversions over different regions of the world based on the analysis of radiosonde data. Hosler (1961) has reported areas with high frequency of inversions being characterized by a higher frequency of clear nights with light winds and vice-versa. The study by Baker et al (1969) showed that a decrease in frequency and intensity indicated an increased urban influence on the temperature of the region. Wendler and Nicpon (1975) found inversion strength increasing with decreasing cloudiness, wind speed and net radiation. Myrick et al (1994) noted that median depths of ground-based early morning inversions

Keywords. Surface inversion; frequency of inversion; inversion depth; inversion strength. 
Table 1. Data availability (total days) in winter for stations north of $20^{\circ} \mathrm{N}$.

\begin{tabular}{|c|c|c|c|c|c|c|c|c|c|c|c|c|}
\hline Year & $\mathrm{AGT}$ & AHM & BWN & CAL & $\mathrm{DBH}$ & DLH & GHT & GWL & JDP & LKN & NGP & PTL \\
\hline 1971 & - & 79 & 27 & 90 & - & 88 & 86 & - & 84 & 81 & 90 & - \\
\hline 1972 & - & 86 & 73 & 90 & - & 89 & 88 & - & 80 & 86 & 88 & - \\
\hline 1973 & - & 84 & 84 & 90 & - & 86 & 65 & - & 88 & 84 & 89 & - \\
\hline 1974 & - & 72 & 73 & 88 & - & 89 & 81 & - & 89 & 88 & 89 & - \\
\hline 1975 & - & 82 & 87 & 89 & - & 90 & 89 & - & 88 & 88 & 90 & - \\
\hline 1976 & - & 85 & 88 & 83 & - & 91 & 85 & - & 85 & 87 & 91 & - \\
\hline 1977 & - & 85 & 86 & 83 & - & 89 & 90 & - & 71 & 82 & 90 & 23 \\
\hline 1978 & 27 & 82 & 89 & 88 & 28 & 89 & 90 & 15 & 84 & 88 & 86 & 84 \\
\hline 1979 & 85 & 78 & 86 & 58 & 84 & 89 & 84 & 66 & 69 & 83 & 78 & 86 \\
\hline 1980 & 88 & 84 & 80 & 89 & 78 & 91 & 79 & 78 & 67 & 86 & 82 & 82 \\
\hline 1981 & 90 & 80 & 85 & 80 & 90 & 90 & 75 & 82 & 78 & 84 & 87 & 88 \\
\hline 1982 & 87 & 79 & 89 & 72 & 86 & 89 & 89 & 67 & 55 & 90 & 85 & 88 \\
\hline 1983 & 88 & 74 & 86 & 88 & 46 & 90 & 63 & 74 & 59 & 82 & 83 & 89 \\
\hline 1984 & 52 & 83 & 89 & 85 & 14 & 90 & 53 & 60 & 84 & 86 & 60 & 90 \\
\hline 1985 & 54 & 75 & 90 & 86 & 56 & 90 & 87 & 75 & 88 & 83 & 88 & 89 \\
\hline 1986 & 69 & 81 & 88 & 89 & 86 & 89 & 83 & 56 & 87 & 88 & 90 & 86 \\
\hline 1987 & 68 & 76 & 80 & 90 & 76 & 86 & 88 & 76 & 87 & 88 & 90 & 88 \\
\hline 1988 & 84 & 78 & 88 & 91 & 71 & 87 & 90 & 84 & 88 & 90 & 91 & 91 \\
\hline 1989 & 74 & 80 & 86 & 89 & 84 & 88 & 88 & 77 & 90 & 86 & 90 & 87 \\
\hline 1990 & 86 & 74 & 89 & 89 & 54 & 88 & 87 & 83 & 86 & 83 & 87 & 80 \\
\hline 1991 & 73 & 80 & 89 & 90 & 75 & 90 & 85 & 58 & 69 & 70 & 90 & 64 \\
\hline 1992 & 82 & 86 & 91 & 91 & 71 & 89 & 89 & 81 & 85 & 91 & 90 & 67 \\
\hline 1993 & 84 & 84 & 89 & 90 & 89 & 90 & 85 & 82 & 86 & 88 & 89 & 89 \\
\hline 1994 & 75 & 78 & 88 & 90 & 85 & 90 & 86 & 80 & 85 & 89 & 90 & 85 \\
\hline 1995 & 85 & 87 & 88 & 89 & 55 & 89 & 86 & 80 & 86 & 86 & 89 & 85 \\
\hline 1996 & 84 & 74 & 80 & 90 & 88 & 91 & 91 & 85 & 85 & 82 & 89 & 78 \\
\hline 1997 & 81 & 85 & 90 & 90 & 85 & 90 & 88 & 85 & 85 & 75 & 90 & 85 \\
\hline 1998 & 72 & 85 & 90 & 90 & 85 & 90 & 89 & 76 & 89 & 88 & 88 & 87 \\
\hline 1999 & 59 & 79 & 59 & 89 & 63 & 90 & 90 & 81 & 86 & 90 & 82 & 89 \\
\hline 2000 & 30 & 82 & 70 & 90 & 43 & 91 & 90 & 60 & 85 & 90 & 91 & 90 \\
\hline
\end{tabular}

were typically $414 \mathrm{~m}$ irrespective of season with spring slightly lower at $315 \mathrm{~m}$, while Janhall et al (2006) reported that morning temperature inversions resulted in high concentrations of traffic related pollutants including $\mathrm{CO}, \mathrm{NO}$, and $\mathrm{NO}_{2}$. Bourne et al (2009) examined the trends and variability in surface inversion parameters and found an increasing trend in inversion depth and strength with both parameters showing a distinct shift from positive to negative anomalies in late 1970's. Studies of inversion characteristics are available over the Indian region too, e.g., Ananthakrishnan and Rangarajan (1963), Sivaramakrishnan et al (1972), Chaudhary (1982, 1983), Viswanadham and Pinaka Pani (1994), Suresh (2000), etc. They found that stable layer occurred on $75 \%$ of the occasions and frequencies of inversions were much higher for stations located north of $20^{\circ} \mathrm{N}$ as compared to the stations south of $20^{\circ} \mathrm{N}$. They also reported maximum frequencies of inversion over eastern and southwestern regions of north India while minimum frequencies were observed in the western parts. A significant increasing trend in the frequencies of nocturnal inversions over Chennai was attributed to rapid urbanization. Studies of surface inversions over India are few and have been done for limited stations and short periods of time, mostly prior to the 1970's. To document the changes that have taken place since then, we have studied the annual and decadal variations in surface inversions over twenty stations in India for the period 1971-2000 during winter.

\section{Data and methodology}

Daily radiosonde data from India Meteorological Department (IMD) at 00 UTC for 20 stations well distributed over India for the period 19712000 in the winter months (December, January and February) are analysed to study the annual as well as decadal variations in surface inversion parameters. As surface inversions are to be studied, we have considered data up to $800 \mathrm{hPa}$ only $(\sim 2 \mathrm{~km})$. 
Surface inversion characteristics

Table 2. Data availability (total days) in winter for stations south of $20^{\circ} \mathrm{N}$.

\begin{tabular}{|c|c|c|c|c|c|c|c|c|}
\hline Year & BMB & $\mathrm{CHN}$ & HYD & MDS & $\mathrm{MNC}$ & PBL & PJM & TRV \\
\hline 1971 & 89 & 89 & 30 & 85 & 81 & 87 & 28 & 84 \\
\hline 1972 & 83 & 89 & 79 & 89 & 88 & 85 & 82 & 89 \\
\hline 1973 & 81 & 84 & 78 & 85 & 87 & 82 & 76 & 79 \\
\hline 1974 & 85 & 79 & 64 & 85 & 74 & 86 & 84 & 82 \\
\hline 1975 & 79 & 86 & 86 & 83 & 87 & 74 & 57 & 88 \\
\hline 1976 & 89 & 77 & 77 & 85 & 85 & 66 & 79 & 89 \\
\hline 1977 & 84 & 79 & 82 & 87 & 87 & 86 & 79 & 89 \\
\hline 1978 & 84 & 83 & 86 & 90 & 76 & 84 & 82 & 84 \\
\hline 1979 & 69 & 77 & 84 & 88 & 80 & 87 & 82 & 88 \\
\hline 1980 & 84 & 87 & 90 & 81 & 74 & 87 & 79 & 91 \\
\hline 1981 & 81 & 87 & 83 & 90 & 77 & 90 & 85 & 90 \\
\hline 1982 & 88 & 86 & 88 & 90 & 64 & 90 & 87 & 88 \\
\hline 1983 & 73 & 89 & 87 & 88 & 82 & 89 & 87 & 86 \\
\hline 1984 & 82 & 88 & 87 & 84 & 88 & 46 & 87 & 89 \\
\hline 1985 & 72 & 86 & 86 & 88 & 86 & 85 & 84 & 90 \\
\hline 1986 & 88 & 87 & 87 & 90 & 79 & 74 & 88 & 89 \\
\hline 1987 & 85 & 63 & 90 & 88 & 82 & 89 & 84 & 90 \\
\hline 1988 & 91 & 74 & 90 & 88 & 70 & 87 & 86 & 91 \\
\hline 1989 & 90 & 68 & 75 & 89 & 87 & 65 & 83 & 90 \\
\hline 1990 & 88 & 77 & 90 & 87 & 89 & 23 & 80 & 88 \\
\hline 1991 & 86 & 74 & 88 & 87 & 79 & 74 & 62 & 86 \\
\hline 1992 & 89 & 87 & 87 & 87 & 72 & 86 & 90 & 89 \\
\hline 1993 & 90 & 81 & 86 & 88 & 90 & 79 & 84 & 89 \\
\hline 1994 & 89 & 86 & 89 & 87 & 89 & 85 & 88 & 90 \\
\hline 1995 & 88 & 84 & 86 & 88 & 81 & 79 & 74 & 88 \\
\hline 1996 & 91 & 88 & 83 & 90 & 86 & 77 & 83 & 91 \\
\hline 1997 & 88 & 90 & 85 & 87 & 82 & 86 & 83 & 89 \\
\hline 1998 & 87 & 89 & 83 & 90 & 90 & 66 & 88 & 87 \\
\hline 1999 & 90 & 90 & 89 & 89 & 90 & 87 & 88 & 88 \\
\hline 2000 & 91 & 90 & 91 & 90 & 89 & 89 & 86 & 77 \\
\hline
\end{tabular}

The Chronometric (C) and Fan (F) type radiosondes which were used in India in the 1950's and 1960's were replaced by Audio Modulated (AM) type in the late 1960's. To avoid inconsistencies in data caused by instrument change, we have used data from 1971 onwards when uniform data was available as the $\mathrm{C}$ and $\mathrm{F}$ type sondes were replaced by AM type sondes (Kothawale and Rupa Kumar 2002). Before permanent archival, the data is processed and several checks were applied to ensure homogeneity (Srivastava et al 1992). Inconsistencies do occur despite these checks, thus, before analyzing we have discarded data whenever abnormal values were found. The observations at standard levels are available at a resolution of $\sim 500 \mathrm{~m}$. We have incorporated data at significant levels in the standard levels, so we could get a resolution of $\sim 200-250 \mathrm{~m}$. As per WMO convention, pressure is accurate to $\sim \pm 1-2 \mathrm{hPa}$ and temperatures are accurate to $\pm 0.5^{\circ} \mathrm{C}$ up to $20 \mathrm{~km}$. Wind accuracy is $\sim 1 \mathrm{~m} / \mathrm{s}$ and $5^{\circ}$ for speed and direction, respectively. Tables 1 and 2 give the number of days for which data is available for each station, yearwise, in the winter months. A maximum of 90 days is possible for each year with leap years having 91 days.

The stations have been divided into two regions according to their location as shown in figure 1 . The region north of $20^{\circ} \mathrm{N}$ is designated as $\mathrm{R} 1$ and there are 12 stations in this region, viz., Agartala (AGT), Ahmedabad (AHM), Bhubaneswar (BWN), Kolkata (CAL), Dibrugarh (DBH), Delhi (DLH), Guwahati (GHT), Gwalior (GWL), Jodhpur (JDP), Lucknow (LKN), Nagpur (NGP) and Patiala (PTL). R2 which is south of $20^{\circ} \mathrm{N}$ has eight stations, viz., Mumbai (BMB), Cochin (CHN), Hyderabad (HYD), Chennai (MDS), Minicoy (MNC), Port Blair (PBL), Panjim (PJM) and Trivandrum (TRV). The reason for the demarcation is that most of R1 is under the influence of western disturbances in winter while $\mathrm{R} 2$ is a peninsular region. The stations' latitude and longitude are shown in table 3 .

Ground-based or surface inversion (hereafter simply inversions) is defined as the layer from 


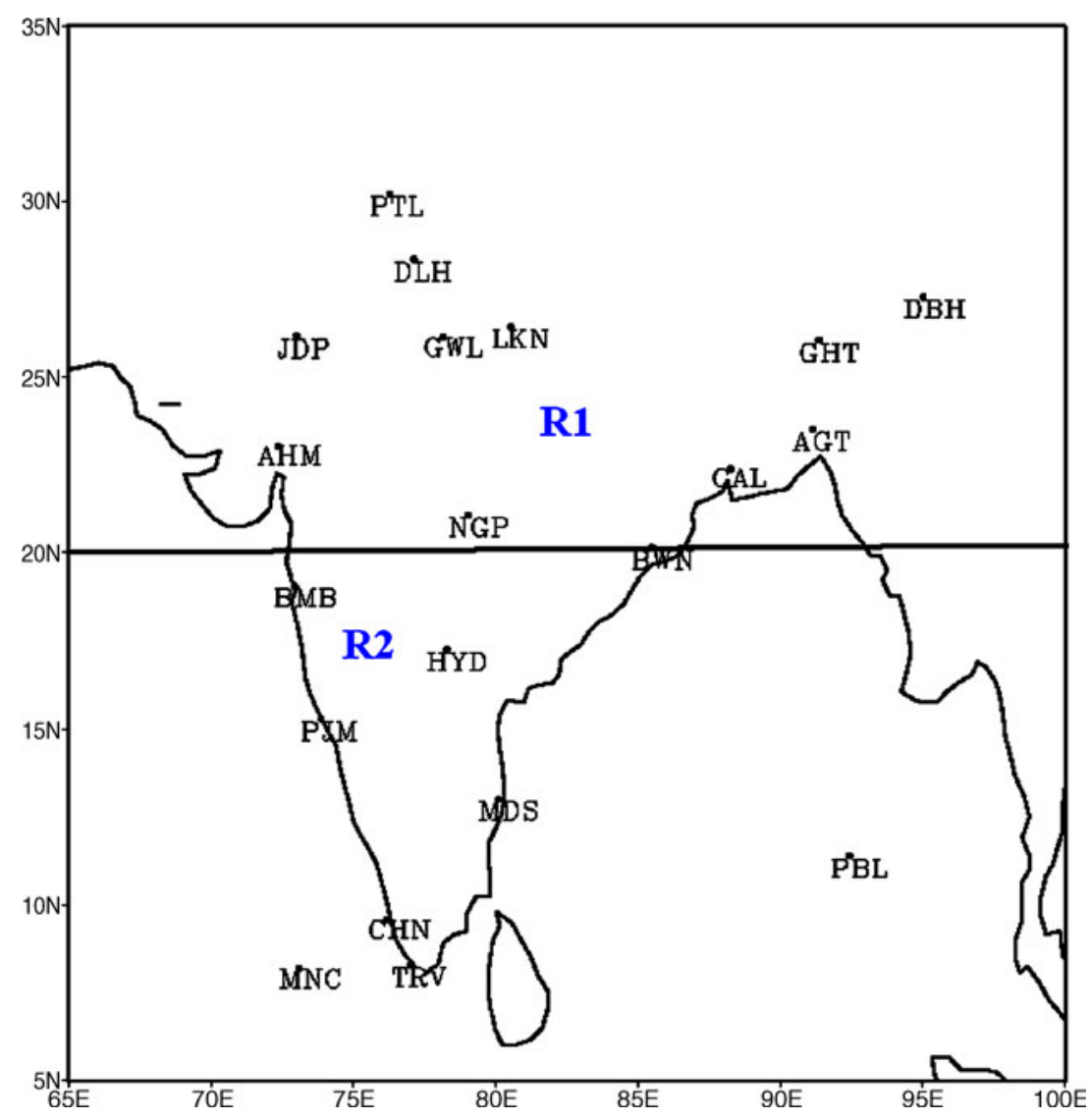

Figure 1. Map showing location of the stations.

the surface in which an increase in air temperature is observed. The top of the inversion is the height above which temperature first decreased with elevation. The frequency distribution of the inversion layers during the winter months are obtained for the three decades, viz., 1971-1980 (1st decade), 1981-1990 (2nd decade) and 1991-2000 (3rd decade) to understand their secular variations. The annual and the decadal variations in inversion depth and strength as well as the changes in the wind speed through the inversion layer are also studied.

The basic characteristics of inversion are: (a) depth $(\Delta h$ meter) which is the height of the top of the inversion from the ground and (b) strength $\left(\Delta T^{\circ} \mathrm{C}\right)$ which is the temperature difference between the top of the inversion and the ground. Based on its depth the inversion is classified as shallow, moderate, deep and very deep as:

$$
\begin{aligned}
& \text { Shallow }: \Delta h=0-200 \mathrm{~m} \\
& \text { Moderate }: \Delta h=201-400 \mathrm{~m} \\
& \text { Deep }: \Delta h=401-600 \mathrm{~m} \\
& \text { Very deep }: \Delta h>600 \mathrm{~m} .
\end{aligned}
$$

Similarly, the inversion is classified as weak, moderate, strong and very strong based on its strength as:

Weak $\quad: \Delta T=0-2^{\circ} \mathrm{C}$

Moderate $: \Delta T=2-6^{\circ} \mathrm{C}$

Strong : $\Delta T=6-10^{\circ} \mathrm{C}$

Very strong : $\Delta T>10^{\circ} \mathrm{C}$.

\section{Results and discussion}

\subsection{Frequency distribution of inversions}

Table 3 gives the frequency distribution of the inversions for all stations in R1 and R2. It is clear from the table that the inversion frequencies are $\sim 20-60 \%$ higher in $\mathrm{R} 1$ as compared to $\mathrm{R} 2$ in all the decades. Further, the frequency of inversions increased from the 1st to the 3rd decade for all stations in R1 except GWL, NGP and PTL. Though these three stations show frequencies of $\sim 90 \%$ in all the decades, a slight decrease of $\sim 3 \%$ is observed from the 1 st to the 3rd decade. Comparatively, 
Table 3. Frequency distribution (\%) of surface inversions.

\begin{tabular}{|c|c|c|c|c|c|c|c|}
\hline \multirow{2}{*}{$\begin{array}{l}\text { Stations } \\
\text { Agartala (AGT) }\end{array}$} & \multicolumn{2}{|c|}{$\begin{array}{l}\text { Latitude } \\
\left({ }^{\circ} \mathrm{N}\right)\end{array}$} & \multicolumn{2}{|c|}{$\begin{array}{l}\text { Longitude } \\
\qquad\left({ }^{\circ} \mathrm{E}\right)\end{array}$} & \multirow{2}{*}{$\frac{1971-1980}{88}$} & \multirow{2}{*}{$\begin{array}{c}1981-1990 \\
89\end{array}$} & \multirow{2}{*}{$\begin{array}{c}1991-2000 \\
92\end{array}$} \\
\hline & 23 & 53 & 91 & 15 & & & \\
\hline Ahmedabad (AHM) & 23 & 04 & 72 & 38 & 84 & 86 & 91 \\
\hline Bhubaneshwar (BWN) & 20 & 15 & 85 & 50 & 41 & 65 & 79 \\
\hline Kolkata (CAL) & 22 & 39 & 88 & 27 & 71 & 76 & 88 \\
\hline Dibrugarh (DBH) & 27 & 29 & 95 & 01 & 67 & 77 & 73 \\
\hline New Delhi (DLH) & 28 & 35 & 77 & 12 & 88 & 88 & 92 \\
\hline Guwahati (GHT) & 26 & 06 & 91 & 35 & 64 & 80 & 79 \\
\hline Gwalior (GWL) & 26 & 14 & 78 & 15 & 92 & 94 & 89 \\
\hline Jodhpur (JDP) & 26 & 18 & 73 & 01 & 87 & 79 & 91 \\
\hline Lucknow (LKN) & 26 & 45 & 80 & 53 & 77 & 73 & 77 \\
\hline Nagpur (NGP) & 21 & 06 & 79 & 03 & 93 & 84 & 90 \\
\hline Patiala (PTL) & 30 & 20 & 76 & 28 & 95 & 93 & 91 \\
\hline Mumbai (BMB) & 19 & 07 & 72 & 51 & 77 & 84 & 92 \\
\hline Cochin $(\mathrm{CHN})$ & 10 & 09 & 76 & 24 & 11 & 16 & 25 \\
\hline Hyderabad (HYD) & 17 & 27 & 78 & 28 & 23 & 46 & 56 \\
\hline Chennai (MDS) & 13 & 00 & 80 & 11 & 31 & 50 & 58 \\
\hline Minicoy (MNC) & 08 & 18 & 73 & 09 & 8 & 16 & 23 \\
\hline Port Blair (PBL) & 11 & 40 & 92 & 43 & 6 & 11 & 11 \\
\hline Panjim (PJM) & 15 & 29 & 73 & 49 & 50 & 70 & 74 \\
\hline Trivandrum (TRV) & 08 & 28 & 76 & 57 & 4 & 8 & 35 \\
\hline
\end{tabular}

lower frequencies $(\sim 4-31 \%$ in the 1st decade to $\sim 11-58 \%$ in the 3rd decade) are observed in R2 at all stations except BMB and PJM where it ranges from $\sim 50-77 \%$ in the 1st decade to $74-92 \%$ in the 3rd decade. Though the frequencies are lower, all stations in R2 show an increase in the frequency of inversions from the 1 st to the 3rd decade.

\subsection{Annual variations in inversion depth and strength}

The annual variations in the inversion depth (figure 2) show that all stations in R1 except DLH, GWL, JDP and NGP (where trends are not significant) show a decline in the inversion depth significant at $99 \%$ level. The maximum decline of $12.3 \mathrm{~m} /$ year is observed at AGT and the minimum decline is observed at CAL (3.3 m/year). In R2, a decreasing trend in inversion depth $(\sim 4 \mathrm{~m} /$ year $)$ is seen at BMB, HYD and PJM significant at $99 \%$ level. While an increasing trend in inversion depth is not observed at any of the stations in R1, three stations located in $\mathrm{R} 2$ show an increase in inversion depth ranging from $3-8.5 \mathrm{~m} /$ year significant at $99 \%$ level for $\mathrm{CHN}$ and $\mathrm{MNC}$ and at $95 \%$ level for MDS. No significant trend is observed at PBL and TRV.

Half of the stations located in R1 show an increasing trend in inversion strength (figure 3) ranging from $0.03-0.06^{\circ} \mathrm{C} /$ year significant at $99 \%$ level for BWN, DLH and JDP and at 95\% level for AGT, AHM and CAL. The remaining six, viz., DBH, GHT, GWL, LKN, NGP and PTL are among the stations that do not show any significant trend. In R2, all stations except BMB, MNC and TRV show an increase in the strength of the inversions from $0.02-0.05^{\circ} \mathrm{C} /$ year significant at 99\% level for PBL and PJM and at $95 \%$ level for CHN, HYD and MDS.

\subsection{Decadal variations in inversion depth}

Figure 4 shows the decadal variations in inversion depth. It is observed that shallow inversions are absent for all stations in R1 except CAL and BWN where frequency of $\sim 20 \%$ in the 1 st decade decreases to $<5 \%$ in the 3rd decade. Moderate inversions are absent in the 1st decade for all stations. The frequency generally increases by $\sim 20 \%$ from the 2nd to the 3rd decade for AHM, BWN, AGT, CAL, DBH and GHT. For the other stations, low frequency $(<15 \%)$ is observed in the 2 nd and 3rd decades. Frequency of deep inversions decreases from $80 \%$ in the 1 st to $\sim 50 \%$ in the 2 nd decade and to $\sim 20-30 \%$ in the 3rd decade for all stations. Very deep inversions with low frequencies in all the decades are observed at all stations except PTL, JDP, GWL, NGP and DLH. Over these stations, frequency increases from $20 \%$ in the 1 st decade to $30 \%$ in the 3rd decade. NGP shows high 

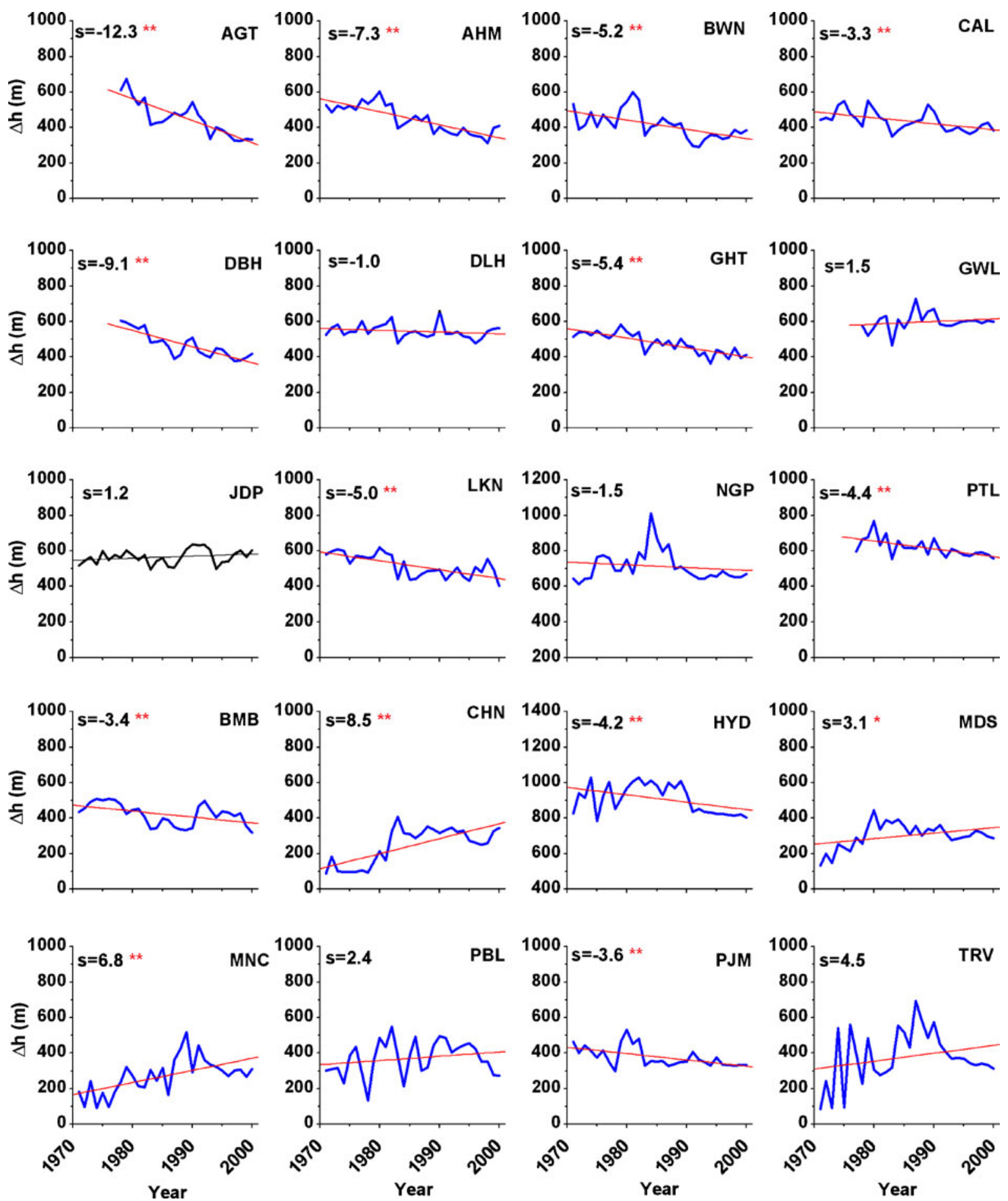

Figure 2. Annual variations in inversion depth (trends significant at 95\% (99\%) level are marked by * (**)).

frequency of very deep inversions increasing from $\sim 50 \%$ in the 1 st decade to $\sim 70 \%$ in the 2 nd and $3 \mathrm{rd}$ decades.

Frequencies of shallow inversions in $\mathrm{R} 2$ decrease sharply from the 1st to the 2nd decade and are very low or absent in the 3rd decade for all stations except HYD where no frequency in this range is observed. Moderate inversions are not observed in the 1st decade for any of the stations. An increase in the frequency $(\sim 20-40 \%)$ of moderate inversions from the 2 nd to the $3 \mathrm{rd}$ decade is seen for all stations except BMB where a $20 \%$ decrease is observed. The frequency of deep inversion decreases by $\sim 40-50 \%$ from the 1st to the 3rd decade for nearly all the stations. Very deep inversions are absent for all stations except HYD 

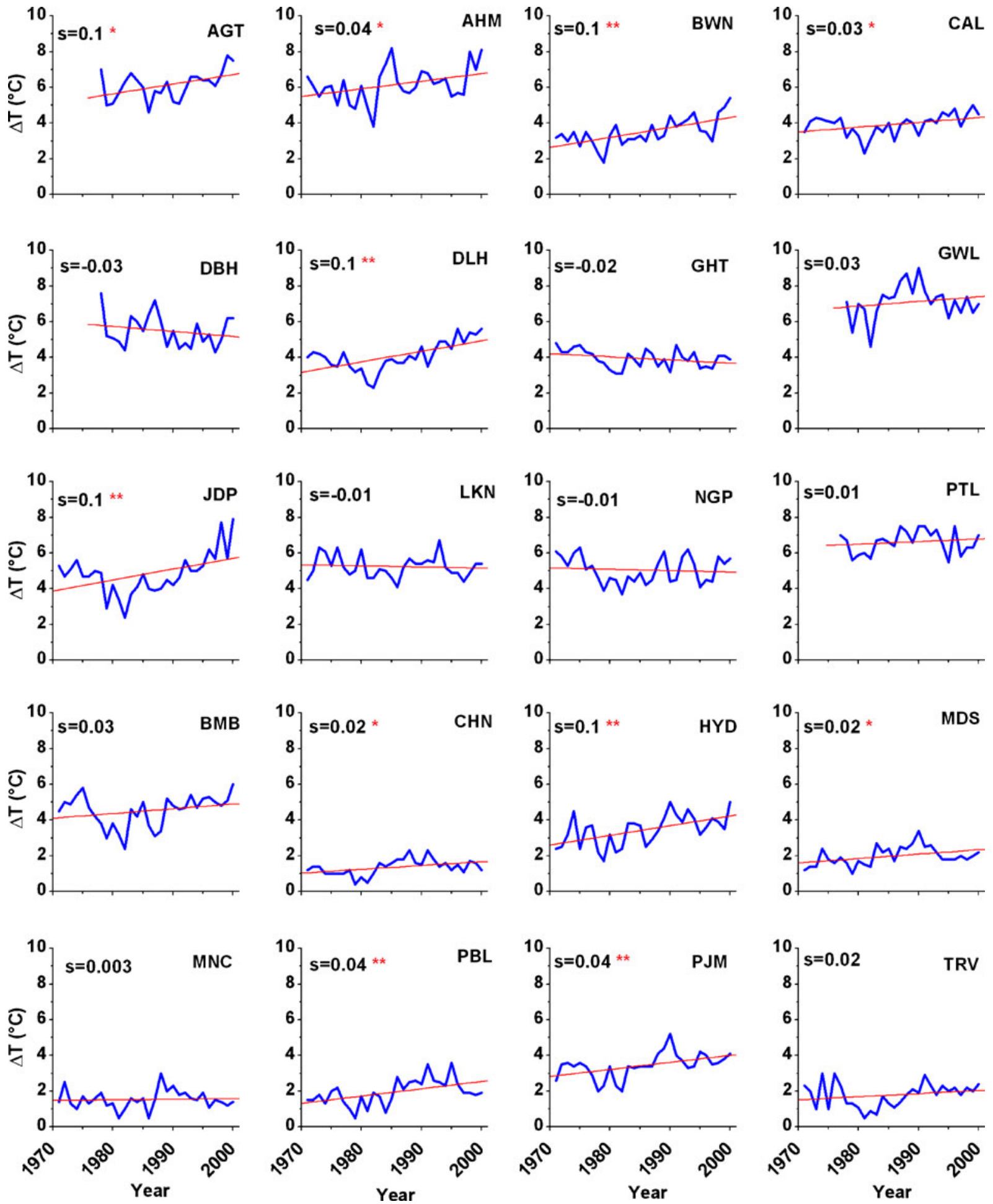

Figure 3. Annual variations in inversion strength (trends significant at $95 \%(99 \%)$ level are marked by $*(* *))$.

where frequencies increase from the 1 st $(70 \%)$ to the 3rd $(\sim 90 \%)$ decade.

\subsection{Decadal variations in inversion strength}

Frequency of weak inversions in R1 (figure 5) decreases from the 1st to the 3rd decade. Most of the inversions are either moderate or strong for all the stations. For DLH, GHT and CAL, the maximum frequency occurs in moderate inversions for all decades though a slight decrease is observed from the 1 st to the 3rd decade. Moderate inversions are found to decrease from $\sim 40-60 \%$ in the 1st decade to $30-55 \%$ in the 3rd decade for PTL, 

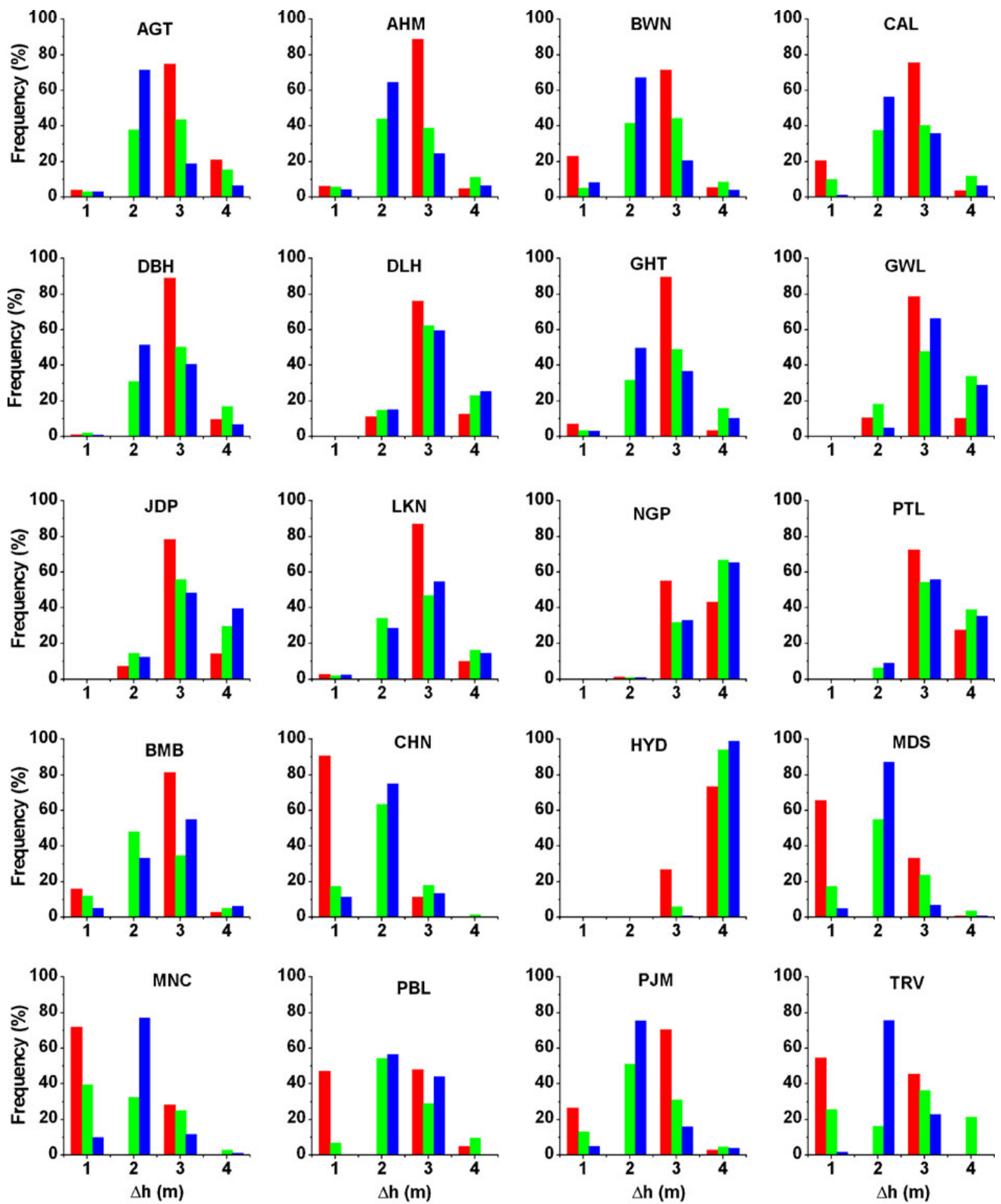

$1^{\text {st }}$ Decade $\quad 2^{\text {nd }}$ Decade $\quad 3^{\text {rd }}$ Decade

\section{$1=0-200 \quad 2=201-400 \quad 3=401-600 \quad 4=>600$}

Figure 4. Decadal variations in inversion depth.

JDP, GWL, NGP, AHM, LKN and AGT. A 10\% increase in moderate inversions from the 1st to the 3rd decade is observed at BWN. Similarly, slight increase $(\sim 5-10 \%)$ in strong inversions from the 1st to the 3rd decade is seen at PTL, GWL, NGP, AHM, LKN, JDP and AGT while a decrease from the 1st $(42 \%)$ to the 3rd decade $(38 \%)$ is seen at DBH. For DLH, CAL and GHT, frequencies 
Surface inversion characteristics
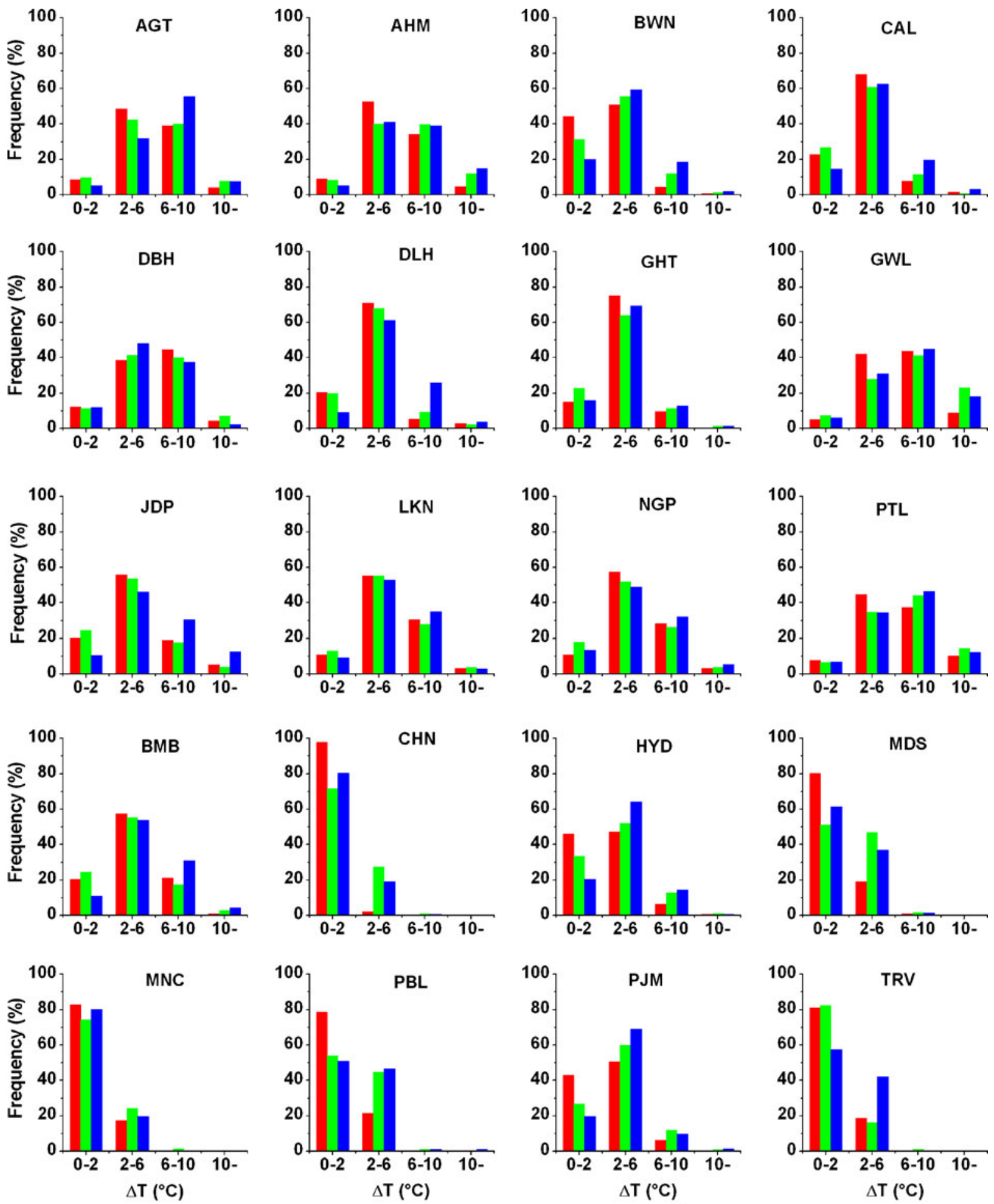

\section{$1^{\text {st }}$ Decade \\ $2^{\text {nd }}$ Decade \\ $3^{\text {rd }}$ Decade}

Figure 5. Decadal variations in inversion strength.

of strong inversions are low though an increase is observed from the 1 st to the 3rd decade ( $~ 5 \%-$ $\sim 20 \%$ ). The frequencies of very strong inversions are either low $(<20 \%)$ or are absent.

In R2, frequency of weak inversions is $80 \%$ in the 1st decade for CHN, MNC, TRV and PBL.
This reduces to $\sim 50-70 \%$ in the 2 nd decade and increases to $\sim 60-80 \%$ in the 3rd decade for $\mathrm{CHN}$, MNC and MDS. A decrease to $55 \%$ from the 2 nd to the 3rd decade is observed for TRV and PBL while PJM and BMB show a reduction of $50 \%$ from the 1st to 3rd decade. For moderate inversions, 

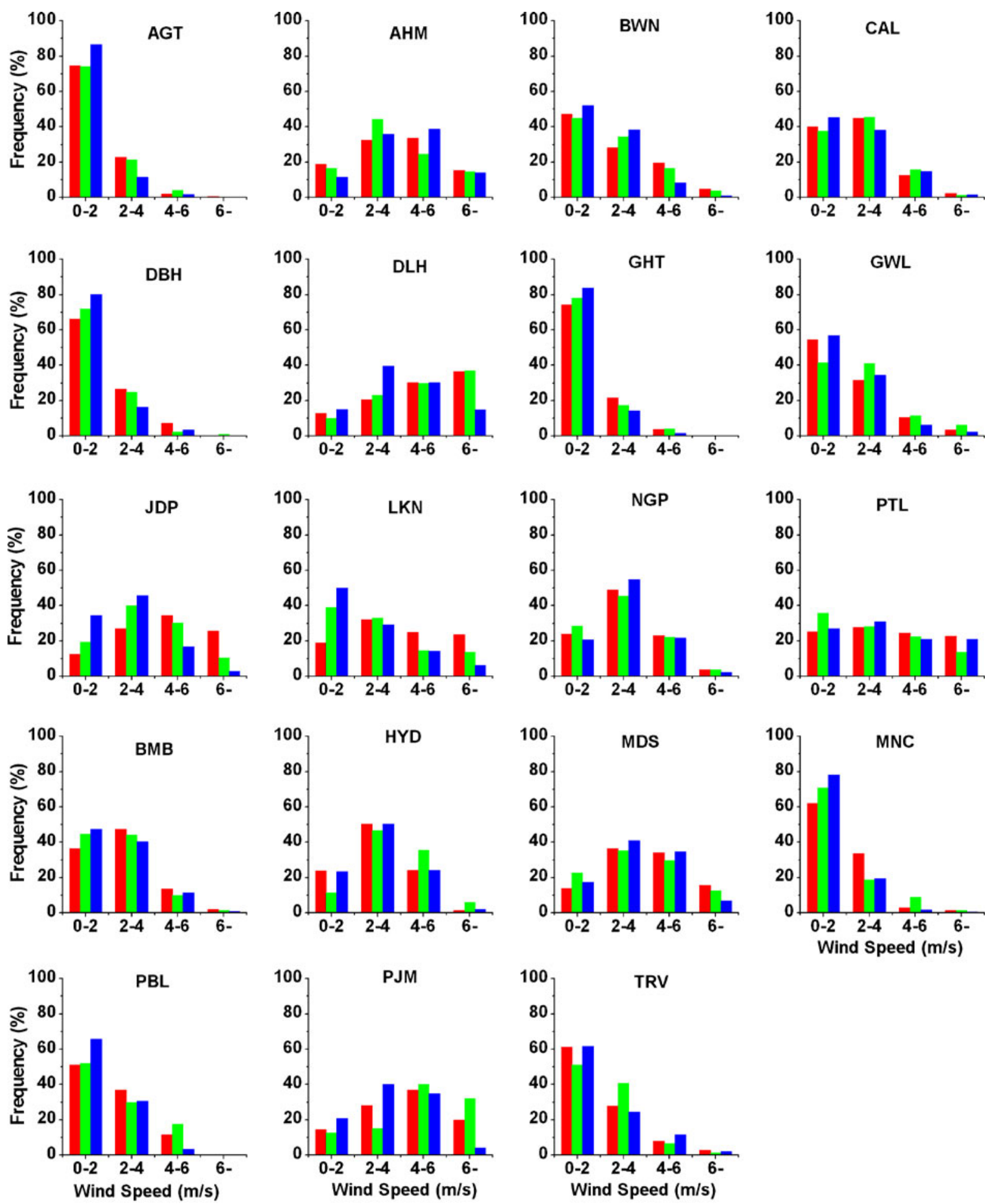

$1^{\text {st }}$ Decade

$2^{\text {nd }}$ Decade

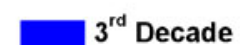

Figure 6. Decadal variations in the wind speed through inversion layer.

frequencies do not show any decadal variation over BMB while it increases over PJM and HYD from the 1st $(\sim 45 \%)$ to the 3rd $(\sim 65 \%)$ decade. For the other stations, though the frequencies are low, they generally show an increase from the 1st to the 3rd decade. For strong inversions, BMB shows an increase from the 1st $(\sim 20 \%)$ to the 3rd (30\%) decade. HYD too shows an increase in frequency form the 1st to the 3rd decade though the values are lower $(\sim 10 \%-18 \%)$. For the other stations, frequencies are very low or absent. Very strong inversions are almost absent in R2. 
Several researchers have attributed the reduction in inversion depth and strength to the increase in warm air advection, aerosols, greenhouse gases, etc. (e.g., Bradley et al 1993; Abdul-Wahab 2003; Abdul-Wahab et al 2004; Kassomenos and Koletsis 2005). But they have also mentioned that it is difficult to identify a specific reason due to strong interaction between many potential factors. Over India, warm air advection is rare in the winter season and a continuous record of aerosols and greenhouse gases during the study period is not available. Therefore, we believe that urbanization, industrialization and a steady increase in urban population are possibly some of the causes for the observed changes in inversion depth and strength during the study period.

\subsection{Wind speed through inversion layer}

Figure 6 shows the frequency distribution of wind speed through the inversion layer for the three decades. In R1, frequency of weak winds $(0-2 \mathrm{~m} / \mathrm{s})$ is $>65 \%$ for AGT, DBH and GHT in the 1st decade increasing to $>80 \%$ in the 3rd decade. A $10 \%$ decrease in the frequency of moderate wind $(2-4 \mathrm{~m} / \mathrm{s})$ from the 1 st to the $3 r d$ decade and very low frequency of strong winds $(4-6 \mathrm{~m} / \mathrm{s})$ are observed over these stations. Very strong winds $(>6 \mathrm{~m} / \mathrm{s})$ are absent. For the other stations in R1 except DLH, frequencies are evenly distributed for weak and moderate winds, with an increasing trend observed from the 1st to the 3rd decade for most of the stations. The frequency of strong winds decreases from $\sim 20-30 \%$ in the 1 st to $\sim 10 \%$ in the 3rd decade. Very strong wind frequency generally decreases from the 1 st to the 3rd decade $(\sim 20 \%$ to $<10 \%$ ). DLH also shows increase in weak and moderate winds from the 1st to the 3rd decade. Frequency of strong winds remains unchanged at $\sim 30 \%$ for all the three decades while a $50 \%$ reduction in the frequency of very strong winds from the 1 st to the 3rd decade is observed.

For the R2 region, frequencies of weak winds either increase from the 1 st to the $3 r d$ decade or are same for all the stations. Winds for CHN are not plotted due to the unavailability of data. Moderate winds at $\mathrm{BMB}, \mathrm{MNC}, \mathrm{PBL}$ and TRV show a decrease of $\sim 8-10 \%$ from the 1 st to the 3rd decade, MDS and PJM show a slight increase and for HYD, there is no decadal change. Low frequencies $(<10 \%)$ of strong winds are observed at BMB, MNC, PBL and TRV while for HYD, MDS and PJM, frequencies are $\sim 35-40 \%$ in all decades. BMB, HYD, MNC, PBL and TRV have negligible frequencies of very strong winds whereas it reduces by $\sim 50 \%$ from the 1 st to the 3 rd decade for MDS and PJM.
Wind speed influences the movement and dispersion of emissions and together with wind direction, it influences the distribution of pollutants. A decrease in wind speed helps in sustaining the inversion and increasing its strength. For most of the stations in R1, frequencies of weak and moderate winds are more than that of strong or very strong winds. With the exception of a few stations, when winds are strong or very strong, the frequencies generally decrease from the 1 st to the 3rd decade. A similar trend is observed for most stations in R2. The weak and moderate winds sustained the observed inversions in R1 and R2 and a decrease in the frequency of strong and very strong winds from the 1 st to the 3 rd decade probably increased the frequency of inversions from the 1st to the 3rd decade. These results are in agreement with those obtained by Rao et al (2004) and Nandankar (1999) where a significant decreasing trend in wind speed was reported. They also observed calm winds under stable conditions during night time, which led to poor diffusion of the pollutants released in the atmosphere.

\section{Conclusions}

Radiosonde data for the period 1971-2000 for the winter months (December, January, February) has been analyzed to study quantitatively the secular variations in ground-based inversions. Inversion frequency in R1 (stations north of $20^{\circ} \mathrm{N}$ ) was $\sim 20$ $60 \%$ higher in all the decades compared to $\mathrm{R} 2$ (stations south of $20^{\circ} \mathrm{N}$ ). Almost all stations in R1 and $\mathrm{R} 2$ show increase in the frequency of inversions from the 1st to the 3rd decade. The inversions are characterized according to their depth and strength. Annual variations in depth and strength of inversions show that nearly all stations in R1 and three stations in R2 show a decline in inversion depth significant at $99 \%$ level. An increasing trend in inversion depth is not observed in any of the stations in R1 while three stations in R2, viz., CHN, MDS and MNC show significant increasing trend. About half the stations in $\mathrm{R} 1$ and $\mathrm{R} 2$ show significant increase in inversion strength while in the other half, though increasing trends are observed, they are not significant.

Over the decades at most stations analyzed, inversions are shallower but stronger. With the exception of a few stations, wind speeds are either weak or moderate, the frequencies increasing from the 1st to the 3rd decade. Strong wind frequencies are low and very strong winds are absent; thus facilitating the formation and sustenance of inversions. Since inversions have a detrimental effect on the concentration of pollutants and their dispersal and may cause fog formation, information about 
these layers may be used by planners for identifying areas for industrial development and expansion of cities.

\section{Acknowledgements}

The authors sincerely thank the Director, Indian Institute of Tropical Meteorology, for providing the facilities and support during the course of this study. They also thank the Head, Forecasting Research Division for his encouragement. They gratefully acknowledge the funding support from DST vide project no. ES/48/ICRP/006/2005.

\section{References}

Abdul-Wahab S A 2003 Analysis of thermal inversions in the Khareef Salalah region in the Sultanate of Oman; $J$. Geophys. Res. 108(D9) 4274, doi: 10.1029/2002JD003083.

Abdul-Wahab S A, Al-Saifi S Y, Alrumhi B A, Abdulraheem M Y and Al-Uraimi M 2004 Determination of the features of low-level temperature inversions above a suburban site in Oman using radiosonde measurements: Long term analysis; J. Geophys. Res. 109 D20101, doi: 10.1029/2004JD004543.

Ananthakrishnan R and Rangarajan S 1963 Inversions and stable layers in the free atmosphere over India - Part I; Indian J. Meteor. Geophys. 14 173-189.

Baker D G, Enz J W and Paulus H J 1969 Frequency, duration, commencement time and intensity of temperature inversions at St. Paul-Minneapolis; J. Appl. Meteorol. 8 $747-753$.

Bourne S M, Bhatt U S, Zhang J and Thoman R 2009 Observed and modeled surface-based temperature inversions in Alaska: Trends and variability; 21st Conference on Climatic Variability and Change 9B-6.

Bradley R S, Keimig F T and Diaz H F 1993 Recent changes in the North American Arctic boundary layer in winter; J. Geophys. Res. 98(D5) 8851-8858.
Chaudhary H M 1982 Frequencies of stable layers in the planetary boundary layer over India (Part-I); Technical Report 91, India Meteorological Department.

Chaudhary H M 1983 Frequencies of stable layers in the planetary boundary layer over India (Part-II); Technical Report 92, India Meteorological Department.

Hosler C R 1961 Low-level inversion frequency in the contiguous United States; Mon. Weather Rev. 89 319-339.

Janhall S, Olofson K F G, Andersson P U, Pettersson J B $\mathrm{C}$ and Hallquist M 2006 Evolution of the urban aerosol during winter temperature inversion episodes; Atmos. Environ. 40 5355-5366.

Kassomenos P A and Koletsis I G 2005 Seasonal variation of the temperature inversions over Athens, Greece; Int. J. Climatol. 25 1651-1663.

Kothawale D R and Rupa Kumar K 2002 Tropospheric temperature variation over India and links with the Indian summer monsoon; Mausam 53 289-308.

Myrick R H, Sakiyama S K, Angle R P and Sandhu H S 1994 Seasonal mixing heights and inversions at Edmonton, Alberta; Atmos. Environ. 28 723-729.

Nandankar P K 1999 Assimilative capacity of the atmosphere at Lucknow with respect to air pollution; Mausam 50 263-268.

Rao G S P, Jaswal A K and Kumar M S 2004 Effects of urbanization on meteorological parameters; Mausam $\mathbf{5 5}$ 429-440.

Sivaramakrishnan M V, Mokashi R Y and Parameswaran N V 1972 Temperature inversions and stable layers near ground over India; Indian J. Meteor. Geophys. 23 $367-378$.

Srivastava H N, Dewan B N, Dikshit S K, Prakash Rao G S, Singh S S and Rao K R 1992 Decadal trends in climate over India; Mausam 43 7-20.

Suresh R 2000 A simple thermodynamical model to estimate the rate of depletion of nocturnal low level inversion layer; Mausam 51 39-46.

Viswanadham D V and Pinaka Pani V V S N 1994 Atmospheric dispersal capacity over north India; Theor. Appl. Climatol. 48 179-185.

Wendler G and Nicpon P 1975 Low-level temperature inversion in Fairbanks, central Alaska; Mon. Weather Rev. 103 34-44. 